Proceedings of ASME RTD2006:

\title{
EFFECTIVENESS OF ALTERNATIVE RAIL PASSENGER EQUIPMENT CRASHWORTHINESS STRATEGIES
}

\author{
Karina Jacobsen \\ Kristine Severson \\ Volpe National Transportation Systems Center \\ US Department of Transportation \\ Cambridge, Massachusetts 02142 USA \\ Benjamin Perlman \\ Tufts University \\ Department of Mechanical Engineering \\ Medford, Massachusetts 02155 USA
}

\section{ABSTRACT}

Crashworthiness strategies, which include crash energy management (CEM), pushback couplers, and push/pull operation, are evaluated and compared under specific collision conditions. Comparisons of three strategies are evaluated in this paper:

- Push versus Pull Operation (Cab Car Led versus Locomotive Led Consists)

- Conventional versus CEM Consists

- Incremental CEM versus Full-CEM

Rail cars that incorporate CEM are designed to absorb collision energy through crushing of unoccupied structures within the car. Pushback couplers are designed to recede into the draft sill under collision loads and enable the car ends to come into contact, minimizing the likelihood of lateral buckling. Push/pull operation refers to operating either a locomotive (pull mode) or a cab car (push mode) at the leading end of the train.

Five cases using combinations of these three strategies are evaluated. The basic collision scenario for each case analyzed in this paper is a train-to-train collision between like trains. Each train has a locomotive, four coach cars, and a cab car. The impact velocity ranges from 10 to $40 \mathrm{mph}$.

The following five cases are evaluated:

1. All conventional cars with a cab car leading (baseline case)

2. All conventional cars with a locomotive leading

3. Conventional coach cars with pushback couplers, with CEM cab car leading

4. All CEM cars with a cab car leading

5. All CEM cars with a locomotive leading

A one-dimensional lumped-mass collision dynamics model is used to evaluate the effectiveness of each strategy, or combination of strategies, in terms of preserving survivable space for occupants and minimizing secondary impact velocity (SIV). Test data is used to correlate SIV with head, chest, and neck injury. Probability of serious injuries and fatalities are calculated based on calculated car crush and injury values. The maximum crashworthy speed, or the maximum impact speed at which everyone is expected to survive, is calculated for each case.

Of the five cases evaluated, the scenario of a cab car led conventional consist represents the baseline level of crashworthiness. The highest levels of crashworthiness are achieved by a consist of all CEM cars with a locomotive leading, followed by all CEM cars with a cab car leading. The results indicate that incremental improvements in collision safety can be made by judiciously applying different combinations of these crashworthiness strategies. A CEM cab car leading conventional cars that are modified with pushback couplers enhances the level of crashworthiness over a conventional cab car led consist and provides a level of crashworthiness equal to a locomotive leading conventional passenger cars.

\section{INTRODUCTION}

The full-scale testing program, under the Federal Railroad Administration's (FRA) Equipment Safety Research program, proposes and evaluates improvements for the crashworthiness performance of passenger trains in collisions. The testing methodology allows a comparison of conventional equipment to improved designs. Testing of conventional equipment establishes a baseline measure of current crashworthiness performance, and proposing and testing a prototype design demonstrates the level of improvement achieved. Comparisons of the conventional and modified designs are demonstrated 
through direct comparison of test results, as well as through analyses. Extrapolations can then be made to evaluate levels of crashworthiness for similar equipment and varying operating conditions.

The foremost goal of crashworthiness design is to preserve the occupant volume during a collision. Therefore, estimating the number of seats lost to car crush during a collision scenario provides a numerical measure of crashworthiness. The second goal of crashworthiness is to limit the severity of the secondary collision environment, as experienced by the passengers. Measures of the environmental conditions are enumerated by calculating the secondary impact velocities (SIVs) and estimating the likelihood of fatal injuries.

The first part of the program tested the crashworthiness performance of existing conventional passenger cars to establish a baseline. Conventional passenger cars are built to meet static strength requirements at each end. Between body bolsters a conventional car has an underframe of approximately uniform cross section and uniform strength. A large initial force is required to initiate buckling of the underframe. Once initiated, deformation progresses at a lower relatively constant force. As a result, under impact conditions, the lead car of a conventional consist experiences the most significant damage to the occupant compartment.

The next part of this program tested the crashworthiness performance of crash energy management (CEM) equipment. These tests are conducted with passenger cars equipped with crush zones that include a pushback coupler, energy absorbers, and a load distribution mechanism (for cab cars). The tests completed thus far show that CEM equipment provides a higher level of crashworthiness in comparison with conventional equipment. The increasing force-crush characteristic causes the crush zone to collapse in a graceful manner and crush to be distributed to successive crush zones. Design and analysis of a CEM cab car led consist shows that with the combination of specific design features, including a pushback coupler, energy absorbers, load distributor, and an integrated end frame, the likelihood for override at the lead interface will be minimized. Additionally, the likelihood for lateral buckling is minimized by the pushback of the couplers and the graceful collapse of the crush zones at the coupled ends.

This paper uses the results of a model of the full-scale cab car led train-to-train test as a springboard to study the effectiveness of alternative crashworthiness strategies. The model is used to estimate the intrusion into the occupant compartment and the secondary impact conditions for the trainto-train test and extrapolate to additional conditions. To address the crashworthiness performance, the number of fatalities due to loss of occupant volume and probability of fatal injury are the measures of occupant protection. Four cases are evaluated to assess improvements over the minimum level of occupant protection expected for conventional equipment. The concepts in these strategies were based on recently acquired data from accident investigations and the development of improvements the crashworthiness of new passenger rail equipment. The purpose of this paper is to provide a comparison of levels of occupant protection during five likely train configurations.

\section{RESEARCH METHODOLOGY}

Evaluating strategies for improving occupant protection in passenger trains used the following methodology: definition of the level of crashworthiness in equipment currently in use; development of alternative strategies; demonstration of a practical level of improvement; and useful recommendations for enhancing safety in rail transportation.

The flow diagram shown in Figure 1 illustrates the stages of the research process and how the effectiveness study fits into the research program. The initial stage defines the scenario of concern. Assessing passenger rail accident history shows that an in-line train-to-train collision poses a serious challenge to the occupant compartment. Full-scale testing has confirmed that once bulk crushing is initiated in a conventional passenger car, it progresses rapidly into the occupied volume [1,2,3].

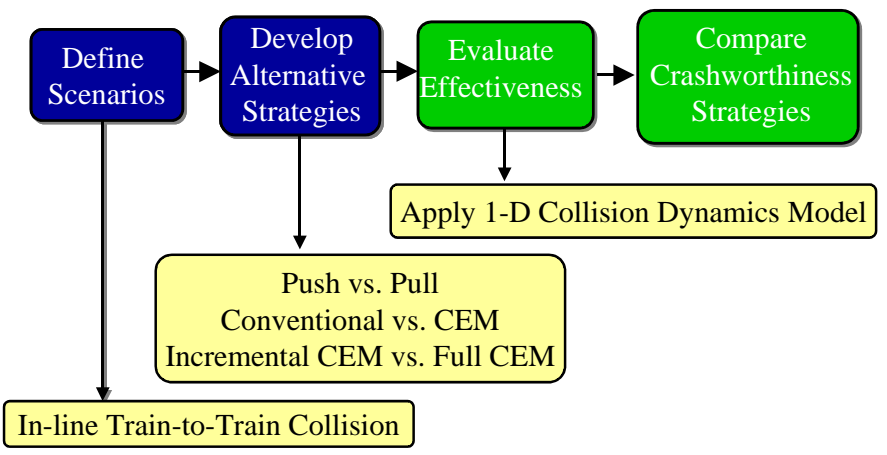

Figure 1. Flow Chart of Research Methodology

Developing alternative strategies considers an evaluation of the spectrum of practical alternatives. Alternatives to cab car led conventional trains include locomotive led conventional trains, trains equipped with CEM technology, and trains equipped with a subset of CEM features. These alternatives were evaluated using a one-dimensional collision dynamics model. Comparisons of the strategies can be quantified in terms of loss of occupant volume and likelihood of fatal injury. Tradeoffs are assessed for the following operational conditions: running trains in push mode (locomotive leading) versus pull mode (cab car leading); conventional trains versus CEM trains; and a combination of the conditions.

Each case scenario was evaluated in a two-part analysis as shown in Figure 2 below. Initial conditions, represented by orange boxes, are the inputs to two models, indicated by light blue boxes. The primary modeling tool is the collision dynamics model. It uses the collision scenario parameters and the force-crush characteristics. In this study, the colliding 
vehicles varied, depending whether a push or pull operation (cab car led passenger train or locomotive led passenger train). Force-crush characteristics measured from previous full-scale tests define nonlinear springs that connect the rigid masses that represent each car. These characteristics distinguish whether a passenger car is conventional or CEM and whether a car end is a cab or a coupled non-cab end. Outputs from the collision dynamics model, shown in the yellow boxes, include the amount of car crush per car end and the gross longitudinal motions of each car in the consist. The damaged, occupied volume estimated from the car crush and translated into the seats lost in each collision case. The final calculation converts a probability of fatality to a number of fatalities due to structural crush during the collision based on the number of occupants in a car.

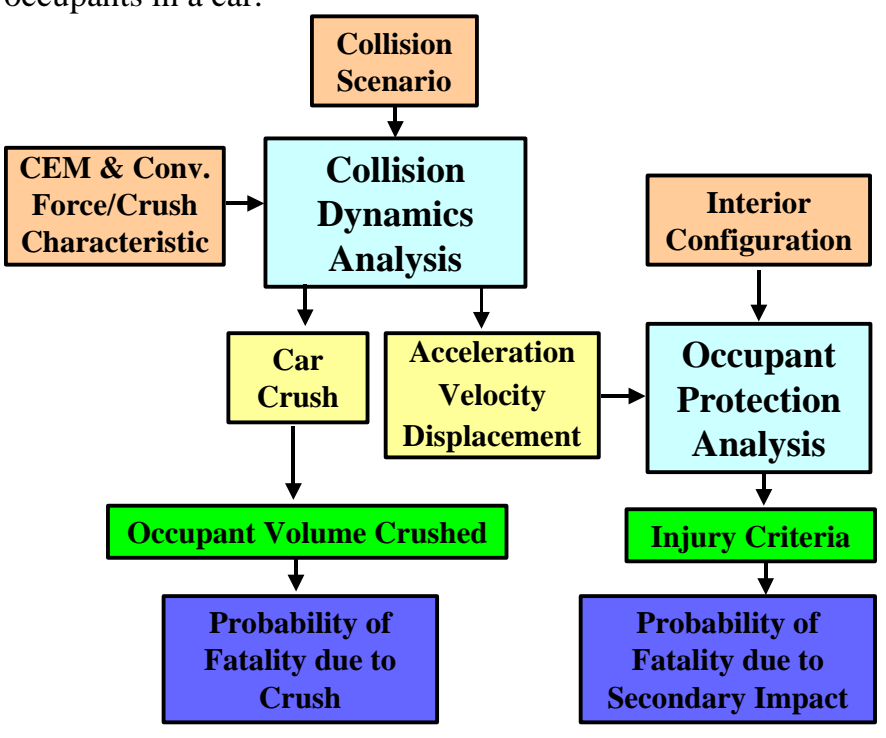

Figure 2. Flow Diagram of Crashworthiness Rating Techniques

The second analysis produces a crashworthiness rating of the secondary collision environment. The interior configuration is required to define the occupant protection analysis. In this study, forward-facing commuter seats were chosen as the most likely seating configuration. The gross motions resulting from the collision dynamics model provide the input parameter that defines the severity of occupant environment. In each of the test cases, the injury criteria associated with secondary impacts was estimated and converted to a complementary probability of fatality due to secondary impact.

The results of these two analyses (shown in the dark blue boxes) are used to make quantitative comparisons of crashworthiness between the baseline and alternative strategies. Both the structural crush and secondary collision environment fatality estimates are based on the number of occupants in the car. The following sections provide the detail of each analysis.

\section{COLLISION CASES}

Five in-line train-to-train collision cases were examined. For each case, the moving train impacts a locomotive led conventional train of equal mass. Each passenger train is made up of a locomotive, four coach cars and a cab car. To represent a strategy, variations of equipment type are applied to the moving consist as shown in Figure 3 below. CEM cars are denoted by red and pushback couplers on conventional cars are indicated by red circles. The cases were chosen to represent the various operating conditions for the alternative strategies.

1. All conventional cars with a cab car leading (baseline case, conventional push operation)

2. All conventional cars with a locomotive leading (conventional pull operation)

3. CEM cab car leading conventional coach cars with pushback couplers, (incremental CEM push operation)

4. All CEM cars with a cab car leading (CEM push operation)

5. All CEM cars with a locomotive leading (CEM pull operation)

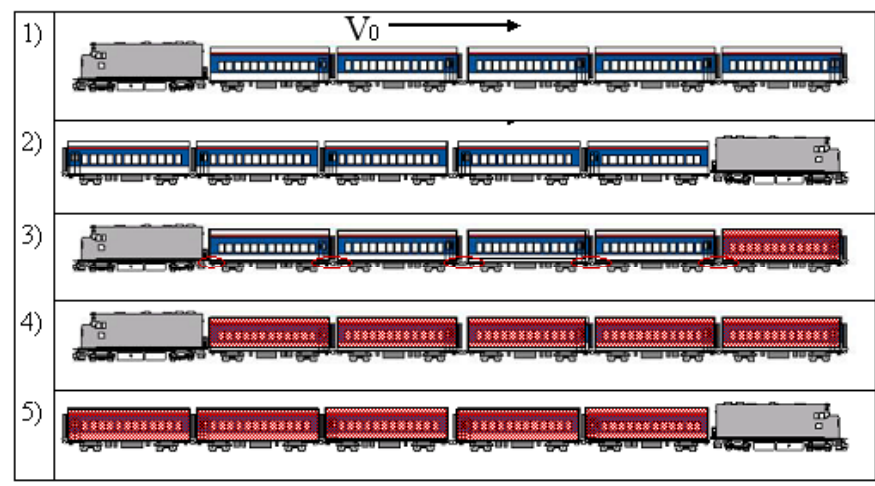

Figure 3. Collision Scenario Cases: Moving Train

\section{COLLISION DYNAMICS ANALYSIS}

The collision dynamics model of an in-line train-to-train collision was implemented using the commercial computer codes, ADAMS [4] and MathCAD [5]. In this model, a moving passenger train impacts a stationary locomotive led train. Both consists are of equal mass. Each mass is allowed one degree of freedom corresponding to the longitudinal motion of the train. Each cab/coach car weighs approximately 95,000 lbs, and each locomotive weighs 260,000 lbs. The closing speeds for the simulated cases range from 10-40 mph with $30 \mathrm{mph}$ being the nominal speed.

Each car body is modeled as a rigid mass and is connected by nonlinear springs that represent the crushing behavior of each car end during a collision. Figure 4 shows a schematic representation of the model with the passenger consist in push operation (cab car leading), i.e., case scenarios 1, 3 and 4. 
Idealized force-crush curves are used to define the spring characteristics.

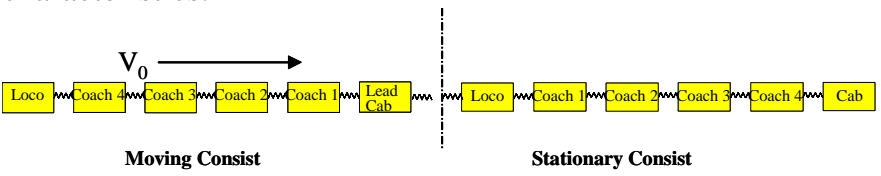

Figure 4. Schematic of Lumped-Mass Collision Dynamics Model

Figure 5 shows the crush behavior used for each end of conventional and CEM passenger cars, measured from fullscale testing $[3,4,5,6]$ and finite element models. Because locomotives have a higher stiffness than passenger cars, the locomotive characteristics are simplified with a linear spring stiffness of $1.0^{*} 10^{7} \mathrm{lb} / \mathrm{ft}$. Figure $5 \mathrm{~b}$ shows the force-crush characteristic post-occupant volume intrusion. The conventional characteristic is calibrated from the full-scale tests. The post-intrusion response depends upon the mode of deformation, i.e., override or engagement. The CEM crush characteristic is estimated from assumed structural behavior.

(a)

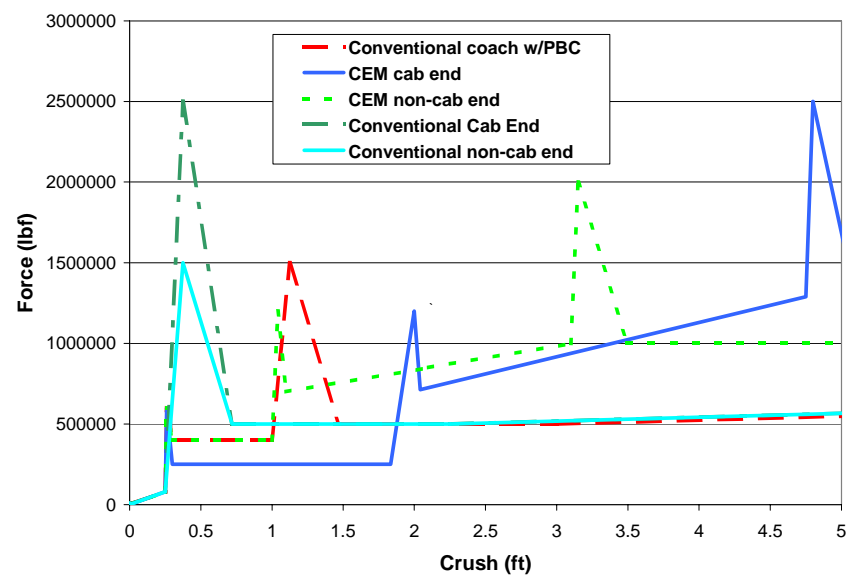

(b)

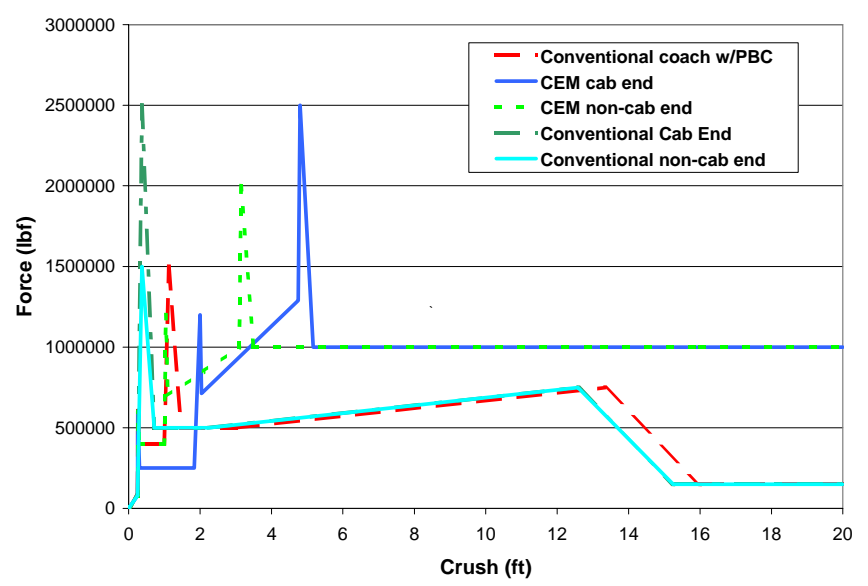

Figure 5. Force-Crush Behavior for (a) 0-5 feet and (b) 020 feet
The typical outcome of conventional equipment in an inline collision is the loss of occupant volume focused on the lead car. This behavior is attributed to the relatively low force required to crush into the car end subsequent to exceeding the peak load (approximately 6 inches of crush). In contrast, the CEM characteristic represents crush that progresses with an increasing step-like load behavior. As the first crush zone collapses and the load required for additional crush increases, crush is initiated at lower load levels at successive crush zones in the consist. As a result, the collision energy can be distributed among unoccupied ends of cars throughout the consist.

The collision dynamics model is used to measure crush at each car end, longitudinal gross motions of the occupant compartment and relative velocity versus relative displacement of the occupant to estimate the secondary impact velocity and resultant injury criteria.

\section{SECONDARY IMPACT ANALYSIS}

The second stage of evaluating crashworthiness is determining the severity of the interior environment. For this study, a simplified occupant analysis was used to make estimates about the impact speed or secondary impact velocity (SIV) of the occupant; injury criteria for the head, neck and chest; and the probability of fatality due to serious injury. The gross motions from each collision dynamics simulation were used to develop a plot of relative speed versus displacement for an occupant. Based upon the maximum allowable travel (freeflight) distance of the occupant, the SIV can be determined from this plot.

To demonstrate how this calculation is interpreted, Figure 6 shows an example of a generic SIV plot. Various seating configurations are shown in relation to allowable travel distances. Typically, a shorter travel distance correlates to a lower SIV, as less time is allowed to build up relative velocity. The plot in Figure 7 shows the severity of SIVs and the possible measures for mitigating the likelihood for injury. A secondary collision environment of less than $18 \mathrm{mph}$ SIV is survivable with conventional interior equipment. Between 18$25 \mathrm{mph}$ SIVs, the interior environment is deemed survivable if compartmentalization is ensured and passive safety modifications are provided in the seat and table designs. Above $25 \mathrm{mph}$, active protection features (i.e. air bags, inflatable structures, seatbelts, etc.) are necessary to reduce the SIVs and consequently bring the injuries within survivable levels. For this study it is assumed that conventional interior equipment is used. 


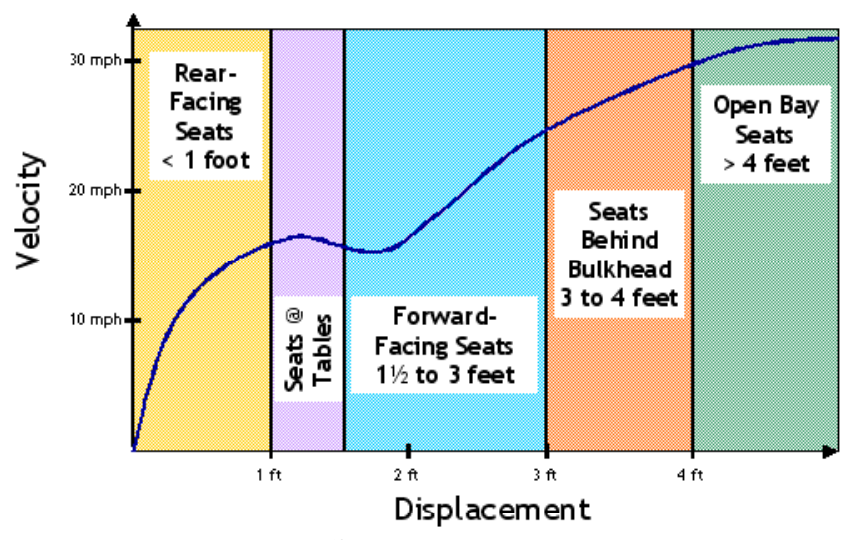

Figure 6. Example SIV Plot Corresponding to Various Seating Configurations

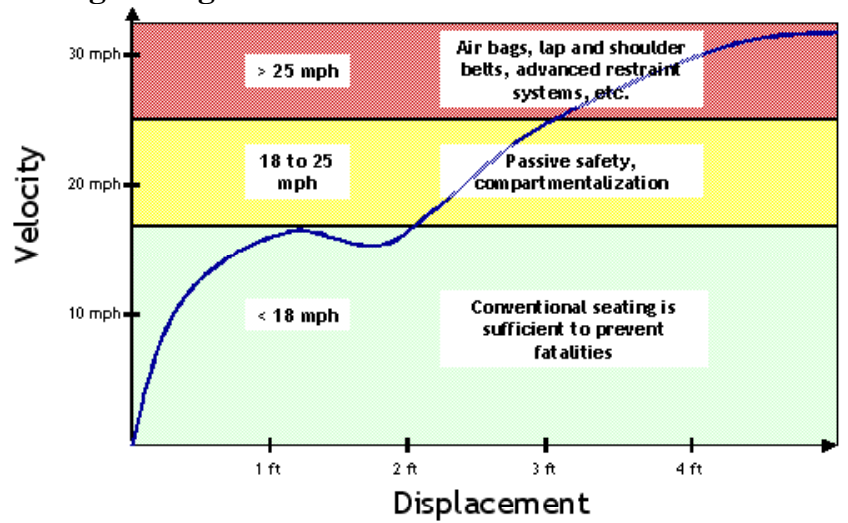

Figure 7. Example SIV Plot with Injury Interpretation

The SIV is used to estimate the injury criteria for the head, neck and chest (the most critical types of bodily injuries). The injury criteria can then be correlated to probability curves representing serious injuries or fatalities. This injury/probability correlation was similar to that used in a previous study of mixed consist crashworthiness [11].

\section{RESULTS}

The calculations of occupant protection were performed for the five case scenarios described above. The results are discussed in order of analyses: loss of occupant volume, secondary impact analysis, injury criteria and a summary of crashworthiness comparisons. For the crush analysis and the secondary impact analysis, the results are evaluated on the car level (focusing on the lead car), train level (trends throughout the consist), and scenario level (trends associated with varying the closing speed).

\section{Occupant Volume Crushed}

A range of closing speeds was examined to observe the rate of the loss of occupant volume, particularly between conventional and CEM equipment. Figure 8 plots the occupied volume damaged for the first passenger car with occupant intrusion in the moving train for incremental closing speeds between $10 \mathrm{mph}$ and $40 \mathrm{mph}$. In the cab leading scenarios, the damaged vehicle is the cab car. In the incremental CEM scenario, either the cab car or first coach may suffer intrusion into the occupied volume. In the locomotive leading scenarios, the damaged car is first coach car coupled to the locomotive.

The closing speed at which a consist can be run while preserving all occupant volume is termed the maximum crashworthy speed. Figure 8 allows the maximum safe speeds to be determined for each collision scenario. The green dashed curve with triangle symbols shows that for the baseline scenario, crush increases dramatically in relation to increasing the closing speed. Between 15-20 mph the space for the operator is lost. Beyond about 3 feet of crush, occupied volume is lost at about a row for every 3 feet of crush. The pink dotted curve with square symbols represents the loss of seats for a locomotive leading conventional train. The results show that up to $25 \mathrm{mph}$, a locomotive leading consist and an incremental CEM consist in push mode will preserve all occupied volume. Correspondingly, up to $35 \mathrm{mph}$ a CEM consist in push or pull mode will preserve all occupied volume.

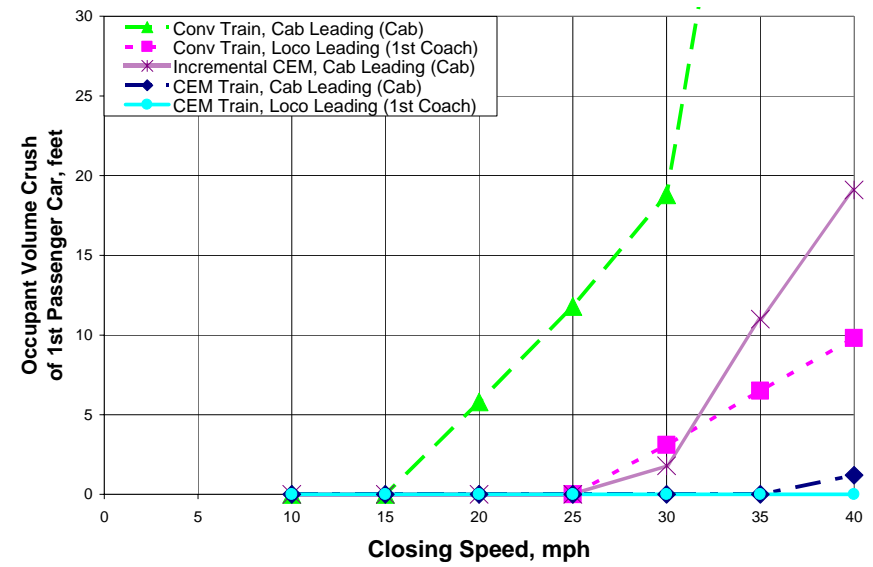

Figure 8. Occupant Volume Crush Results for Varying Closing Speeds

Differences between the curves of these plots are explained by referring back to the force-crush behavior (Figure 5) of the two equipment types. Crush progression highlights one of the benefits of CEM equipment. Because the CEM equipment can distribute the crush to multiple crush zones in a consist made up all CEM cars, the progression of crush into a single car will be slower than a conventional car in a conventional consist. Because car crush progresses rapidly in a conventional car, crush is the limiting factor for the maximum safe closing speed. The occupant analyses in the next section will reveal that consideration of the secondary impact environment is important for comprehensively evaluating the crashworthiness performance of CEM equipment. 


\section{Secondary Impact Velocity}

For this study, the occupant injury due to secondary impacts was calculated using an SIV and correlating to injury criteria. The interior occupant environment was simplified by assuming all seats are forward-facing commuter seats. During an impact scenario, commuter seats allow a free-flight distance of about 2 feet.

The passenger car closest to the impact generally experiences the harshest secondary impact environment out of all the cars in the consist. Figure 9 shows the SIVs for the lead passenger car of the moving consist for each case, at a closing speed of $30 \mathrm{mph}$. Like the sample SIV plot shown in Figure 6, this plot shows the levels of protection required for three ranges of SIVs. This plot shows that a lead CEM car in a consist has a more severe interior environment than the other cases. This environment can be made less hostile with the addition of passive occupant protection, such as ensuring compartmentalization and design modifications made to the seats and tables.

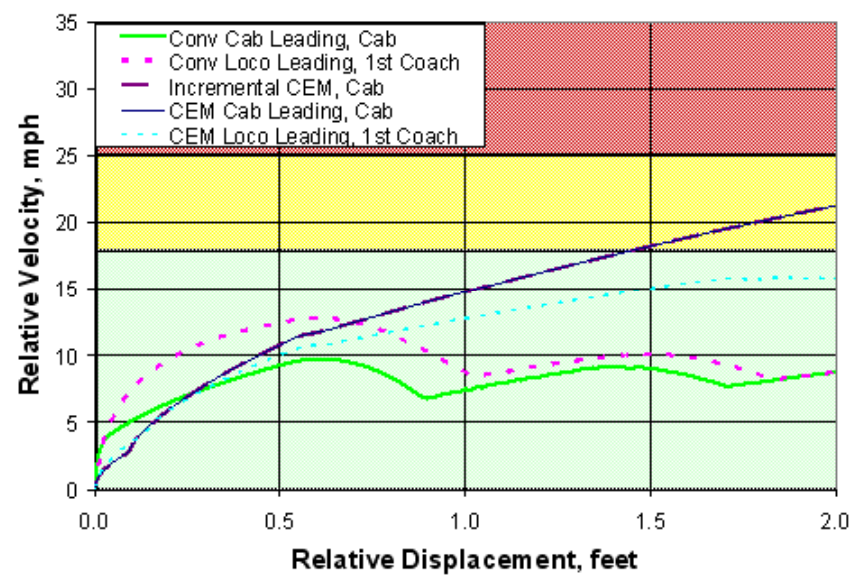

Figure 9. SIV Results for Foremost Passenger Car (Closing Speed of $30 \mathrm{mph}$ )

The bar graph shown in Figure 10 presents the results of each case for each car in the moving consist. From this plot the influence of SIVs throughout the consist at a closing speed of $30 \mathrm{mph}$ can be observed. In the previous plot it was noted that the lead cab car in the CEM consist experienced an SIV of about $22 \mathrm{mph}$. Examining this plot shows that the highest SIVs are experienced in the first two cars in the cab car leading CEM consist, but that the following cars have SIVs in the same range as conventional consists. Additional safety measures can be taken, such as using rear-facing seats, to mitigate the risks associated with SIV in the leading car for CEM equipment. For the conventional consist, all the cars in the consist decelerate at approximately the same rate and consequently have uniform SIVs. Aside from the first two cars in the CEM consist in the locomotive leading CEM consist, all SIVs of the trailing cars are around $10 \mathrm{mph}$, which has nearly zero probability of causing fatal injuries due to secondary impact.

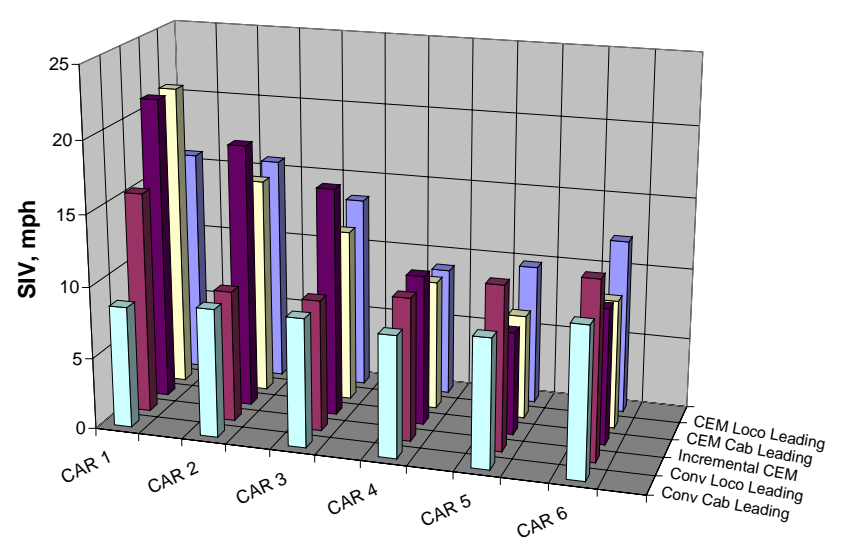

Figure 10. SIV Results at Closing Speed of $30 \mathrm{mph}$

\section{Injury Criteria}

Figure 11 summarizes the likelihood of fatality due to secondary impacts. The likelihood of fatality was calculated based upon the cumulative probability of sustaining an injury to the head, neck or chest of greater than AIS 5, rated a "critical" injury on the Abbreviated Injury Scale (AIS) [12]. This plot shows that secondary impacts are not a factor, except in the case of a CEM cab car leading a consist. For these two cases, the probability of fatality due to a secondary impact is less than $2 \%$.

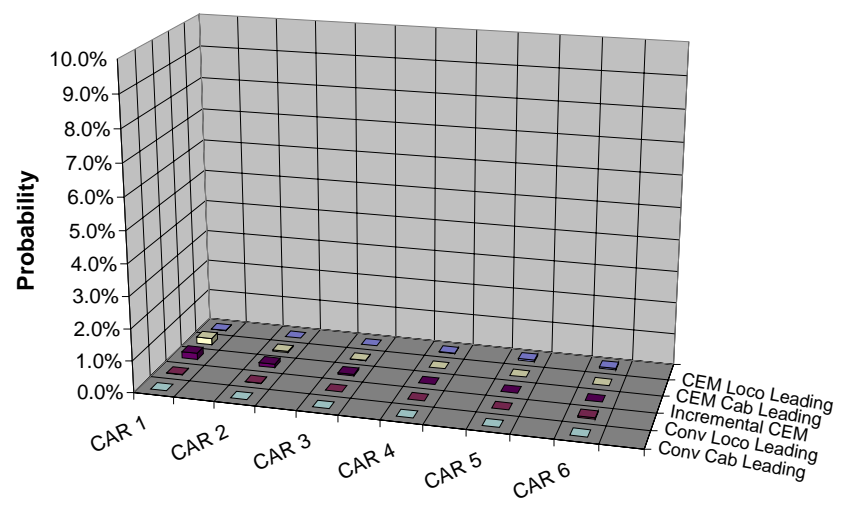

Figure 11. Probability of Fatality due to Secondary Impact

As with the occupied volume, trends are also evaluated for a range of closing speeds, 10-40 mph. The green (dashed) and pink (dotted) curves associated with the conventional consists do not increase with collision speed. For the consists with one or more CEM cars, the SIV increases with closing speed. For a CEM cab car leading a consist, modifications to the seat would be required to maintain a low probability of injury due to secondary impacts. The probability of fatal injury in the lead cab could be mitigated by incorporating strategic occupant protection in this car, such as rear-facing seats with high enough head rests that protect against neck injury. Figure 6 
shows that the use of rear-facing seats allows for a travel distance of between zero and one foot and consequently, results in a low SIV.

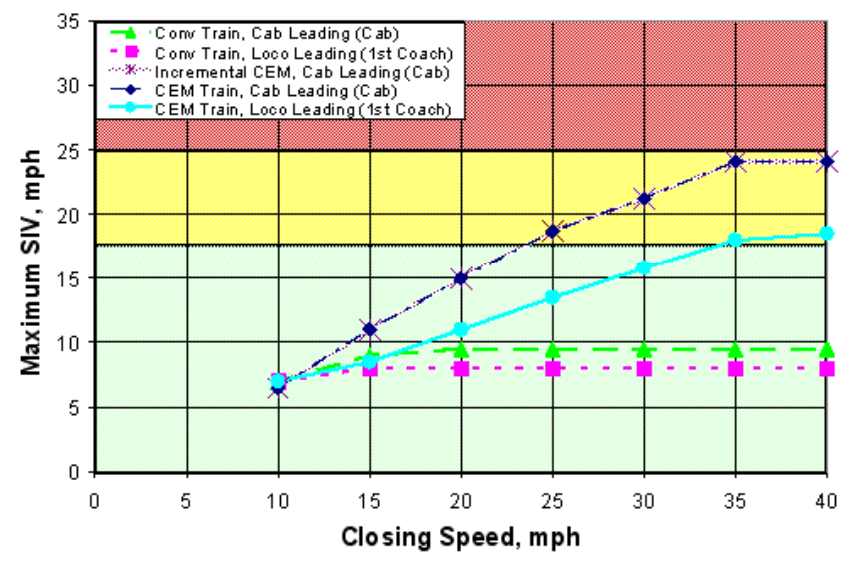

Figure 12. Comparison of Maximum SIVs for Each Scenario

In summary, Figure 12 shows that SIV is a limiting factor for determining the maximum safe closing speed for consists with CEM cars.

\section{Summary of Results}

Table 1 lists the fatalities associated with each collision case at the nominal closing speed of $30 \mathrm{mph}$. To extrapolate the number of fatalities due to crush and secondary impacts, the probabilities of each were applied to a hypothetical fully occupied commuter train. Loss of occupied volume is based on the structural crush with a factor accounting for the build up of crushed structure. The fatalities due to secondary impact are based on the likelihood of sustaining an injury of AIS 5 (rated as “critical”) or above.

Table 1. Summary of Crush and SIV Results (Closing Speed of $30 \mathrm{mph}$ )

\begin{tabular}{|c|c|c|c|c|c|}
\hline & \multicolumn{5}{|c|}{ Make-up of Moving Train } \\
\cline { 2 - 6 } & $\begin{array}{c}\text { Conv Cab } \\
\text { Leading }\end{array}$ & $\begin{array}{c}\text { Conv Loco } \\
\text { Leading }\end{array}$ & $\begin{array}{c}\text { Incremental } \\
\text { CEM }\end{array}$ & $\begin{array}{c}\text { CEM Cab } \\
\text { Leading }\end{array}$ & $\begin{array}{c}\text { CEM Loco } \\
\text { Leading }\end{array}$ \\
\hline $\begin{array}{c}\text { \# of fatalities due to } \\
\text { secondary impact }\end{array}$ & 0 & 0 & $0-4$ & $0-4$ & 0 \\
\hline $\begin{array}{c}\text { \# of fatalities due to } \\
\text { crush }\end{array}$ & $30-40$ & $0-5$ & $0-5$ & 0 & 0 \\
\hline Total & $30-40$ & $0-5$ & $0-9$ & $0-4$ & 0 \\
\hline
\end{tabular}

The first scenario of a cab car leading conventional train sets the baseline for capabilities of current equipment. In this case as much as a third of the lead car (6-8 rows of seats) could be crushed, causing 30-40 fatalities. As was shown in the trend plot of occupied crush (Figure 8), once bulk crushing of a conventional car is initiated, it proceeds very rapidly. Bulk crushing focused on the lead car has been confirmed through full-scale testing, and a large count of fatalities due to such behavior is consistent with accident data.
The second column of the table shows the results of a conventional consist in pull mode. The locomotive has more mass than a cab car but does not protect completely against bulk crushing. Crush is focused on the first passenger car behind the locomotive. At $30 \mathrm{mph}$ crush could intrude into the first row of passenger seats, corresponding to an estimated 0-5 fatalities. At a higher speed, Figure 8 shows that the rate of crush in this car will increase in a similar pattern to the cab car leading case. Pull mode improves the performance over the push mode cab car but does not address the uncontrolled crush behavior of a conventional car. Preventing intrusion into the occupant compartment is the foremost goal of occupant protection strategies. Additionally, locomotive led conventional consists do not protect against rear collisions or override.

The results of an incremental CEM consist are shown in the third column. Defined as a CEM cab car led train with conventional coach cars modified with pushback couplers, this case takes advantage of some of the key features of CEM. The CEM cab car allows for structural damage to be focused on and shared between the two unoccupied ends of the car. A larger amount of collision energy can be absorbed in a CEM car than a conventional one before intrusion into the occupied volume occurs. Consequently, the number of fatalities due to crush is greatly reduced from the baseline case. From full-scale testing and modeling it is understood that the negative effects caused by override of the colliding vehicles will be prevented by the CEM features on the cab car, and lateral buckling will be minimized due to the inclusion of pushback couplers on the conventional cars. An incremental CEM consist provides a similar level of crashworthiness as a conventional locomotive led consist, but an incremental CEM consist can minimize multiple negative modes of deformation.

The last two columns show the improvement demonstrated with full CEM consists. Absorption of the collision energy is shared between ten crush zones on the ends of the passenger cars, allowing the preservation of all occupied volume. As shown in the measure of the SIVs, the lead passenger car of a CEM consist experiences a more severe secondary environment. These calculations of fatalities due to SIVs are performed with the assumption of conventional interior equipment. Numerous studies have shown that improved interior designs, such as rear-facing seats, can reduce this likelihood. The final column represents the potential improvement due to the cumulative benefits of a CEM design strategy and an operational strategy combined.

The conclusions of the CEM scenarios show that the likelihood of fatalities due to crush is greatly improved. The occupant analysis shows that the secondary impact environment plays a larger role in probability of fatalities than in conventional equipment. Strategic modifications to the interior in the lead car will offset such a tradeoff. 


\section{CONCLUSION}

Five equipment/operating scenarios were evaluated for comparisons of crashworthiness protection. The results show the tradeoffs that are made by selecting one of the four alternative strategies. In summary, CEM provides increased protection in terms of preserving the occupied volume. Conventional equipment experiences a rapidly increasing loss of occupant volume in relation to closing speed. The interior environment in the leading car of a CEM consist is more severe than a conventional consist, but, with modifications to the interior, the likelihood for injury can be managed (e.g., rearfacing seats).

For conventional equipment, car crush is the limiting factor for determining the crashworthiness performance, and, for CEM equipment, secondary impacts are the limiting factor for determining maximum safe collision speeds. For the baseline scenario, a cab car led train at $13 \mathrm{mph}$ preserves all occupant volume. A locomotive led conventional consist and a consist with a CEM cab car and conventional car with pushback couplers offer the same maximum safe operating speed of 25$30 \mathrm{mph}$. A consist of all CEM cars provides the highest level of occupant protection. A cab car led CEM consist has a maximum safe collision speed of $30 \mathrm{mph}$ with a conventional interior and $32 \mathrm{mph}$ with a modified interior. A CEM train in pull mode provides the highest level of occupant protection with a maximum safe speed of $35 \mathrm{mph}$ with a conventional interior and $40 \mathrm{mph}$ with a modified interior.

Any of the four alternate strategies proposed in this study will more than double the maximum safe closing speed of the baseline scenario. The scenario involving selective CEM features provides an alternate solution to replacing all conventional cars with CEM cars. This scenario provides a level of crashworthiness equal to a pull operation of conventional equipment, but also allows for transition into a bigger improvement.

The research conducted by the FRA, including this study, was recently used to evaluate the most practical strategies for improving the crashworthiness of Metrolink's fleet of multilevel passenger cars [13]. For the initial release of a procurement for new passenger equipment, specifications for CEM cab cars were included, with the intention of operating CEM cab cars with conventional cars modified with pushback couplers. Additionally, the specification called for all rearfacing seats in the cab cars.

This strategy addresses many of the trends discussed in this paper. The CEM cab car in the lead position manages the collision energy by sharing it between two ends and additionally minimizes the likelihood of override. Similarly, pushback couplers serve the purpose of minimizing the likelihood of lateral buckling between cars. The final issue of CEM causing a more severe secondary environment in the lead car is addressed by the use of rear-facing seats to minimize the distance of travel and the associated SIV.
A month after the release of Metrolink's procurement an amendment was made to include CEM coach cars. When in operation, the new consists will provide a maximum safe collision speed nearly triple the conventional consists. This is an example of strategic inclusion of CEM strategies to enhance crashworthiness.

\section{ACKNOWLEDGEMENTS}

This work was performed as part of the Equipment Safety Research Program sponsored by the Federal Railroad Administration's Office of Research and Development. The authors would like to thank Dr. Tom Tsai, Program Manager, and Claire Orth, Division Chief, Equipment and Operating Practices Research Division, Office of Research and Development, Federal Railroad Administration, for all their support.

\section{REFERENCES}

[1] Tyrell, D., Severson, K., Perlman, A.B., "Single Passenger Rail Car Impact Test Volume I: Overview and Selected Results,” U.S. Department of Transportation, DOT/FRA/ORD00/02.1, March 2000.

[2] Tyrell, D., Severson, K., Perlman, A.B., "Passenger Rail Two-Car Impact Test Volume I: Overview and Selected Results,” U.S. Department of Transportation, DOT/FRA/ORD01/22.I, January 2002.

[3] Tyrell, D., Severson, K., Perlman, A.B., Rancatore, R., "Train-to-Train Impact Test: Analysis of Structural Measurements,” American Society of Mechanical Engineers, Paper No. IMECE2002-33247, November 2002.

[4] ADAMS, Version 2003.0.0, Mechanical Dynamics, Inc. Ann Arbor, Michigan.

[5] Mathcad, Version 2001i, Mathsoft, Corp. Cambridge, MA.

[6] Jacobsen, K., Tyrell, D., Perlman, A.B., "Impact Test of a Crash Energy Management Passenger Rail Car,” RTD200466045, April 2004

[7] Mayville, R.A., Johnson, K.N., Stringfellow, R.G., Tyrell, D.C., "The Development of a Rail Passenger Coach Car Crush Zone,” ASME/IEEE Paper No. ASME RTD 2003-1653, April 2003.

[8] Severson, K., Parent, D., Tyrell, D., "Crash Energy Management Impact Tests: Occupant Tests,” American Society of Mechanical Engineers, Paper No. IMECE200461249, November 2004.

[9] Severson, K., Tyrell, D., Perlman, A.B., "Rail Passenger Equipment Collision Tests: Analysis of Structural Measurements,” American Society of Mechanical Engineers, RTD-Volume 19, 2000. 
[10] Tyrell, D.C., Perlman, A.B., "Evaluation of Rail Passenger Equipment Crashworthiness Strategies," Transportation Research Record No. 1825, pp. 8-14, National Academy Press, 2003.

[11] Severson, K., Tyrell, D., Perlman, A.B., "Analysis of Collision Safety Associated with Conventional and Crash Energy Management Cars Mixed within a Consist," American Society of Mechanical Engineers, Paper No. IMECE200344122, November 2003.

[12] Pike, J.A., Automotive Safety: Anatomy, Injury, Testing and Regulation, Society of Automotive Engineers, 1990.

[13] Tyrell, D., Martinez, E., Severson, K., Jacobsen, K., Parent, D., Priante, M., Perlman, A.B., "Overview of Crash Energy Management Specification for Passenger Rail Equipment,” American Society of Mechanical Engineers, Paper No. RTD2006-94044, May 2006. 